\title{
Editorial Editorial
}

La educación superior se ha expandido notablemente en todo el mundo. El crecimiento reciente ha sido vertiginoso. El siglo pasado cerró con una matrícula universitaria de 100 millones de estudiantes y en casi dos décadas del siglo XXI esta población llegó a 223 millones (UNESCO Institute for Statistics, 2020). Actualmente, la masificación (según Martin Trow, una cobertura entre 30 y 50\%) y la universalización (más de 50\%) son realidad en una gran cantidad de países. ${ }^{1}$ La expansión permitió que jóvenes provenientes de sectores sociales desfavorecidos, tradicionalmente excluidos (por su bajo nivel socioeconómico, su origen étnico o su sexo) ganaran una mayor presencia en las instituciones de educación superior en diversas latitudes, incluso en regiones con pronunciadas desigualdades sociales (Balbachevsky et al., 2019; Chiroleu, 2014; Goastellec y Välimaa, 2019; Zembylas, 2018). Es preciso reconocer este importante logro. Sin embargo, cabe preguntar la medida en la cual la distribución de esas oportunidades educativas ha sido justa y ha permitido disminuir brechas de desigualdad en el ejercicio del derecho a la educación.

Esa pregunta central es la razón por la cual la Revista Latinoamericana de Estudios Educativos dedica el presente número, coordinado por Marisol Silva Laya, a estudiar la equidad y la justicia en educación superior. En este sentido, pone a disposición una serie de estudios y reflexiones de distintos países de América Latina, y de diferentes recortes de la problemática -el aula, la rectoría universitaria, la investigación o la política educativa- indagan el estado en que se encuentran la justicia y la equidad, así como los alcances y límites de algunas de las estrategias probadas para avanzar en ellas. Los temas abordados ofrecen aportes y provocaciones para estimular la discusión sobre un tema clave en el mundo y particularmente en nuestra región.

\footnotetext{
${ }^{1}$ La situación del África subsahariana es muy distinta pues sólo alcanza una tasa de cobertura promedio de $8 \%$.
} 
En América Latina la preocupación por expandir la educación superior se intensificó desde finales del siglo pasado y, al igual que en el ámbito mundial, este crecimiento se aceleró significativamente en los albores del nuevo siglo. Pasó de tener una tasa neta de escolarización de $22 \%$ en 2000 a $43 \%$ en 2017. Hoy la matrícula de educación superior en América Latina supera los 28 millones de estudiantes (UNESCO Institute for Statistics, 2020). Llama la atención el caso de Brasil, donde la matrícula pasó de 2.7 millones de estudiantes en 2000 a 9 millones en 2016 (Balbachevsky et al., 2019), también destaca México, donde se incorporaron 1.9 millones de nuevos estudiantes al sistema en el mismo periodo.

Los ritmos de crecimiento han sido distintos en los diferentes países, en función de su capacidad económica, crecimiento demográfico y consolidación de la escolaridad previa, y ello se refleja en sus tasas brutas de matriculación. Para 2017, Argentina (90\%), Chile (88\%), Perú (71\%) y Uruguay (63\%) se ubicaban ya en la etapa de universalización de la educación superior, mientras que el resto de los países, salvo Honduras (24\%), en la etapa de masificación (UNESCO Institute for Statistics, 2020).

Un análisis de la expansión en la región latinoamericana revela su impulso mediante dos vías. Por un lado, se generaron políticas de equidad para ampliar el acceso a sectores sociales desfavorecidos a través de diferentes acciones: creación de nuevas instituciones públicas, ampliación de la cobertura en las existentes mediante acciones afirmativas, compensación económica mediante becas o créditos, entre otras. Por el otro, se promovió la liberalización de la educación superior al sector privado en el marco del programa neoliberal de los años noventa, donde los organismos multilaterales dictaron los rumbos de la políticas económicas y sociales de los Estados y señalaban que éstos debían centrar sus esfuerzos financieros en apoyar a la educación básica (Canales, 2017). Actualmente, la educación superior privada en Latinoamérica concentra el 54\% de la matrícula ${ }^{2}$ (OCTS-OEI, 2019). Un ejemplo notable del primer caso se encuentra en Argentina con una política de ingreso irrestricto. La

\footnotetext{
${ }^{2}$ Representaba la mayor parte en Chile (84.4\%), Perú (74.7\%), Brasil (73.3\%), El Salvador (69.1\%) y República Dominicana (59.4\%).
} 
segunda vía prevalece en Brasil, Chile (aunque empieza a transformarse), Perú, Colombia, Ecuador, El Salvador y República Dominicana (OCTS-OEI, 2019). Una mezcla de ambas se experimentó en México.

En las políticas de los distintos países por ampliar la base de acceso a la educación terciaria se halla una mezcla de supuestos sobre su relación con el desarrollo económico y la competitividad global de los mercados, la necesidad de apegarse a la institucionalización global de un nuevo modelo de sociedad (Benavides et al., 2015, Gidley et al., 2010) y, por supuesto, la necesidad de responder a una demanda demográfica creciente. En este marco, se registra una tendencia a un crecimiento en la multiplicidad y el número de universidades que, curiosamente, repiten los patrones institucionales y dificultan la imprescindible innovación organizacional y pedagógica para dar cabida a grandes volúmenes de estudiantes no tradicionales con necesidades e intereses diversos. Excepciones notables se encuentran en proyectos universitarios interculturales que buscan atender las diversidades étnicas, pero han tenido que enfrentar cánones añejos y serias limitaciones financieras.

$\mathrm{Al}$ adentrarnos en la reflexión sobre la justicia en la distribución de las oportunidades educativas, vale la pena poner de relieve que en la región se ha documentado el reforzamiento de desigualdades, a pesar de la ampliación del acceso. En el caso de la apertura a la inversión privada, ésta dio pie a la proliferación de instituciones de educación superior con la acreditación de requisitos mínimos y marcos legales permisivos que afectan el nivel organizacional y la calidad de la oferta (Benavides et al., 2015; Canales, 2017). Fueron el refugio para la juventud rechazada en las instituciones públicas de calidad y con escasos recursos para optar por una universidad de élite. En los sistemas públicos, la expansión y la diversificación también dieron origen a circuitos de calidad inferior para los sectores más pobres ya que se crearon instituciones sin las condiciones elementales para ofrecer una formación académica adecuada a las expectativas del estudiantado (Chiroleu, 2014; Silva, 2020; Yuni et al., 2014). Por lo tanto, el crecimiento, lejos de resolver las inequidades educativas asociadas con las desigualdades sociales, ha fortalecido un sistema de desigualdad cualitativa. 
En nuestra región, las oportunidades educativas se siguen distribuyendo en función del origen social. Los y las jóvenes que pertenecen a sectores sociales desfavorecidos enfrentan una variedad de barreras para su acceso y éxito académico. La democratización del acceso sigue siendo una aspiración lejana. La juventud más pobre se enfrenta a la exclusión y está subrepresentada en el mundo universitario. Muestra de ello es que en la mayoría de los países de la región la participación de jóvenes provenientes del quintil más pobre no supera el $5 \%$. En contraste, quienes provienen del último quintil tienen tasas de participación de $50 \%$ y en ocasiones superan el 80\% (CINDA, 2016). Al mismo tiempo, los sectores sociales desfavorecidos padecen una inclusión estratificada en circuitos de menor calidad educativa (Balbachevsky et al., 2019; Villa et al., 2018). Todo ello reproduce las desigualdades sociales preexistentes.

De acuerdo con Altbach (2010), esta tendencia parece tener un carácter global. Este estudioso de la educación terciaria destaca lo paradójico que ha resultado a escala mundial que la ampliación en el acceso haya traído desigualdad a la educación superior, precisamente porque las instituciones que proveen acceso masivo lo hacen con instalaciones, calidad y enfoques muy distintos de los que ofrecen las instituciones de élite. Satisfacer las exigencias de una demanda creciente tensiona los sistemas nacionales. Las respuestas, particularmente en las sociedades más desiguales, privilegiaron el crecimiento cuantitativo, descuidando la calidad y debilitando la responsabilidad de los Estados para garantizar el derecho a la educación superior.

El diseño y la evaluación de acciones destinadas a ampliar las oportunidades educativas para los grupos sociales desfavorecidos requieren una fundamentación sólida en la justicia y la equidad educativa. En América Latina, por mucho tiempo, se ha asimilado la equidad como igualdad de oportunidades, un principio anclado en las políticas neoliberales de los ańos noventa. Tal principio partió de un enfoque igualitario que enmascaraba las profundas desigualdades sociales. Las acciones educativas se dirigieron a ampliar el acceso a la escuela entre sectores sociales excluidos con la intención de compensar las desigualdades, principalmente mediante becas y otros insumos. Sin embargo, las políticas fundamentadas en tal principio se han propuesto alcanzar la equidad sin transformar las condiciones 
estructurales que están en la base de las desigualdades e inequidades (Yuni et al., 2014).

Este enfoque ha sido seriamente cuestionado y empezó a agotarse a finales del siglo pasado frente a un contexto de creciente heterogeneidad cultural y desigualdad económica. En la región se han producido nuevas nociones alejadas del enfoque redistributivo y de igualdad de oportunidades, para impulsar una perspectiva de equidad que hiciera compatibles la transformación social y la competitividad económica (Granja, 1997). En ella es fundamental el reconocimiento de las diferencias y la atención proporcional de las necesidades. Además, se amplía la operacionalización de la equidad y se demanda atender no sólo el acceso, sino también la permanencia y el egreso oportuno.

En América Latina se ha producido conocimiento suficiente para reconstruir un concepto de equidad, basado en la justicia social, que aboga por "mejor distribución económica, mejor reconocimiento del valor de las diferencias y mayor representación en la vida social" (Cuenca, 2012, p. 85). En los últimos años, se ha impulsado el concepto de inclusión social, que parte de reconocer la fragmentación social y la discriminación que sufren grupos minoritarios. Ésta pone en el centro su derecho a aprender, de acuerdo con las necesidades e intereses particulares, y no sólo a asistir a una institución escolar. Hoy, tanto la concepción de equidad como la de inclusión social pugnan por el reconocimiento de la diferencia y de la diversificación educativa que ha quedado de lado en las discusiones, privilegiando la homogeneización y la asimilación de las culturas institucionales y académicas más tradicionales como ideal de éxito universitario.

Sirva este recuento para invitar a reflexionar sobre la necesidad de seguir aportando a la construcción de definiciones de justicia y equidad relevantes para los procesos educativos de la región. Desde nuestro punto de vista, equidad significa articular recursos y procesos en espacios universitarios inclusivos para ofrecer una educación relevante y pertinente a los y las jóvenes provenientes de los estratos sociales desfavorecidos, donde participen con plena titularidad del derecho a la educación para desarrollar aprendizajes significativos que les permitan ampliar sus capacidades y mejorar sus condiciones de vida (Silva, 2020). Se reconoce aquí la importancia de visibi- 
lizar las dimensiones económica, cultural y política del fenómeno que atraviesan la experiencia educativa en su conjunto, vista desde cualquier perspectiva. En un marco global compartido sobre la preocupación por la justicia social y la equidad educativa (Gidley et al., 2010; Goastellec y Välimaa, 2019), América Latina enfrenta desafíos propios, particularmente profundos para la comprensión y la transformación de esta problemática en la región más desigual del planeta.

La tarea convoca la intervención de actores diversos (hacedores de política, instituciones educativas, comunidades académicas, estudiantado) y no puede seguir reducida a ofrecer puentes para el acceso. La demanda es ahora crecer con calidad, ofrecer más a quienes menos tienen y ello implica un compromiso permanente de atención a la realidad de los y las jóvenes para construir modelos educativos pertinentes y espacios inclusivos de convivencia democrática. En América Latina el tránsito hacia la universalización de la educación superior no debe reducirse a un crecimiento cuantitativo del sistema; es imprescindible revertir la inclusión excluyente para avanzar hacia un ejercicio pleno del derecho a este bien público.

Universidad Iberoamericana Ciudad de México

\section{REFERENCIAS}

Altbach, P. (2010, septiembre 23). Trouble with numbers. Times Higher Education. The World University Rankings. Recuperado de https:// www.timeshighereducation.com/cn/features/trouble-with-numbers/413555.article

Balbachevsky, E., Sampaio, H., y Yahn de Andrade, C. (2019). Expanding Access to Higher Education and Its (Limited) Consequences for Social Inclusion: The Brazilian Experience. Social Inclusion, 7(1), 7-17. http://dx.doi.org/10.17645/si.v7i1.1672

Benavides, M., León, J., Haag, F., y Cueva, S. (2015). Expansión y diversificación de la educación superior universitaria, y su relación con la desigualdad y la segregación (Documento de Investigación Núm. 78). Canadá: Grupo de Análisis para el Desarrollo. 
Canales, A. (2010). Evaluación: Elementos del debate internacional. Revista Iberoamericana de Evaluación Educativa, 3(1e), 11-20.

Canales, A. (2017). Los imperativos internacionales de la educación y las desigualdades regionales. En L. Villa, A. Canales y M. Hamui, Expresiones de las desigualdades sociales en espacios universitarios asimétricos (pp. 55-98). UNAM-IIS-Conacyt.

Chiroleu, A. (2014). Desigualdades en educación superior y políticas públicas. Los casos de Argentina, Brasil y Venezuela. Universidades, (59), 9-22.

CINDA. (2016). Educación Superior en Iberoamérica Informe 2016. Informe Nacional México. CINDA-UNIVERSIA. Recuperado de https:// cinda.cl/wp-content/uploads/2019/01/educacion-superior-en-iberoamerica-informe-2016-informe-nacional-mexico.pdf

Cuenca, R. (2012). Sobre justicia social y su relación con la educación en tiempos de desigualdad. Revista Internacional de Educación para la Justicia Social, 1(1), 79-93.

Gidley, J., Hampson, G., y Wheeler, L. (2010). From Access to Success: An Integrated Approach to Quality Higher Education Informed by Social Inclusion Theory and Practice. Higher Education Policy, (23), 123-147. https://doi.org/10.1057/hep.2009.24

Goastellec, G., y Välimaa, J. (2019). Access to Higher Education: An Instrument for Fair Societies? Social Inclusion, 7(1), 1-6. https://doi. org/10.17645/si.v7i1.1841

Granja, J. (1997). Los desplazamientos en el discurso educativo para América Latina. Revista Mexicana de Sociología, 59(3), 161-188.

OCTS-OEI. (2019). Panorama de la Educación Superior en Iberoamérica. Edición 2019. Caracterización de los Sistemas de Educación Superior y de Acreditación Universitaria (núm. 12; Papeles del Observatorio). http://www.redindices.org/attachments/article/115/Papeles $\% 20$ del $\% 20$ Observatorio\%20N\%C2\%BA\%2012.pdf

Silva, M. (2020). La dimensión pedagógica de la equidad en educación superior. Archivos Analiticos de Politicas Educativas, 28(46). https://doi. org/10.14507/epaa.28.5039

UNESCO Institute for Statistics. (2020). UIS.Stat. UIS Statistics. http:// data.uis.unesco.org 
Villa, L., Canales, A., y Hamui, M. (2018). Expresiones de las desigualdades sociales en espacios universitarios asimétricos. México: UNAM-IIS-Conacyt. Yuni, J. A., Meléndez, C. E., y Griselda, A. (2014). Equidad y políticas universitarias: Perspectivas desde latinoamérica. REDU. Revista de Docencia Universitaria, 12(2), 41-60. https://doi.org/10.4995/ redu.2014.5639

Zembylas, M. (2018). Decolonial possibilities in South African higher education: Reconfiguring humanising pedagogies as/with decolonising pedagogies. South African Journal of Education, 38(4). https:// doi.org/10.15700/saje.v38n4a1699 